\title{
Electrochemical Fabrication of Memory Device Based on Conducting Polymer Composites
}

\author{
Qi Chen, Lu Zhao, Chun Li and Gaoquan Shi* \\ Department of Chemistry Tsinghua University Beijing 100084, China
}

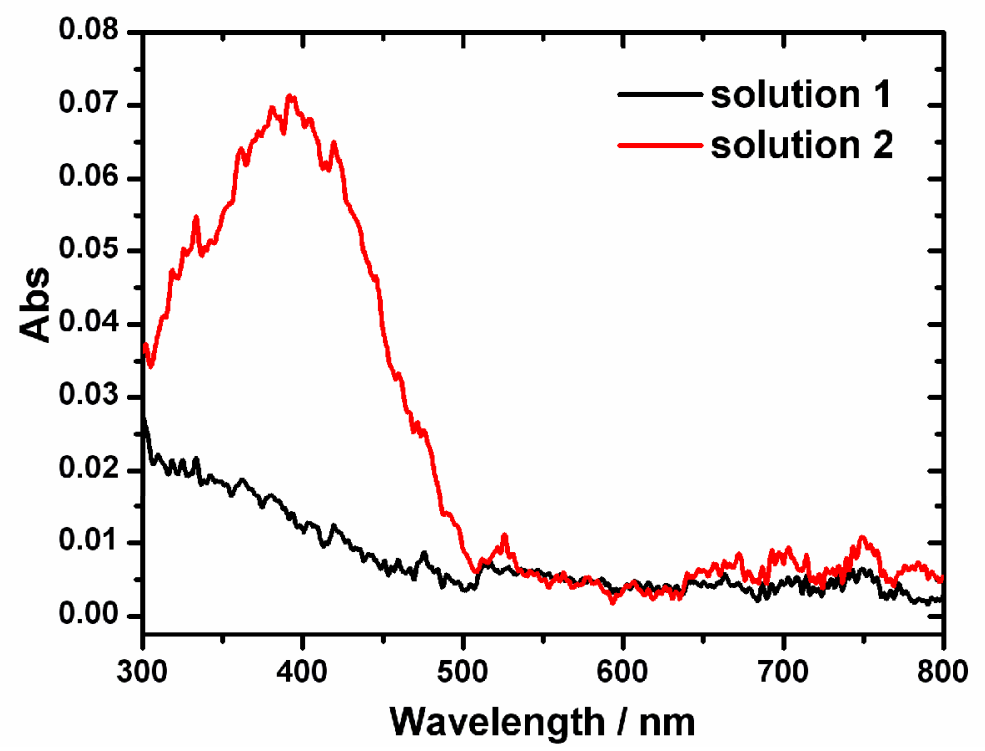

Figure S1. UV/Vis spectra of the $\mathrm{CH}_{2} \mathrm{Cl}_{2}$ soaking solutions of the composite films deposited from the electrolytes containing $0.1 \mathrm{M} 3 \mathrm{HT}$ and $2 \mathrm{mg} \mathrm{mL}^{-1}$ MTGNPs (solution 1) or DTGNPs (solution 2). The films were deposited at a constant applied potential of $2.3 \mathrm{~V}$ (vs. $\mathrm{Ag} / \mathrm{AgCl}$ ) for $300 \mathrm{~s}$ and washed with $\mathrm{CH}_{2} \mathrm{Cl}_{2}$. The working electrode was immersed in $5 \mathrm{~mL} \mathrm{CH}_{2} \mathrm{Cl}_{2}$ for $4 \mathrm{~h}$ before the spectra of soaking solutions were recorded. 